\title{
LA DOBLE VIDA DE SU MERCED EN AMÉRICA ENTRE LOS SIGLOS XVI Y XIX
}

\author{
THE DOUBLE LIFE OF SU MERCED IN AMERICA \\ FROM THE SIXTEENTH TO THE NINETEENTH \\ CENTURY
}

\author{
Virginia Bertolotti \\ Universidad de la República, Uruguay \\ virginia.bertolotti@gmail.com \\ LAURA ÁlVAREz LÓPEz \\ Stockholms universitet \\ laura.alvarez@su.se
}

\begin{abstract}
Resumen: Esta investigación explora la historia americana del originalmente honorífico e ibérico su merced, hoy empleado por millones de hablantes del español en América. A partir de un análisis de 983 concordancias de $s u$ merced extraídas de corpus de datos lingüísticos que va del siglo XVI al XIX, este trabajo describe su sintaxis, pone en relación tradiciones discursivas y cambio lingüístico y muestra que su merced ha tenido dos vías de desarrollo en América a partir de dos prácticas comunicativas bien diferenciadas: la institucional y la interpersonal. En la primera, su merced se ha extinguido; en la segunda, su uso permite advertir el nexo con los empleos actuales.

Palabras clave. su merced; tradiciones discursivas; cambio lingüístico; delocutivos; alocutivos.
\end{abstract}

Abstract: This research explores the history of the originally Iberian honorific title su merced, currently used by millions of Spanish speakers in the Americas. The paper summarises the results of an analysis of 983 occurrences extracted from a corpus of documents written in the Americas between the 16 th and the 19th centuries. The study connects discursive traditions with linguistic change and describes the syntax of su merced. It shows that su merced had two parallel developments in two clearly differentiated communicative practices: in the institutional and the interpersonal spheres. In the institutional sphere su merced has disappeared, while in the interpersonal sphere, it is linked to current usage.

Keywords: su merced; discursive traditions; linguistic change; delocutives; alocutives.

Recepción: 26 de agosto de 2018; aceptación: 9 de enero de 2019.

D.R. ( ) 2020. Nueva Revista de Filología Hispánica Licencia Creative Commons Attribution-NonCommercial (CC BY-NC) 4.0 International 
INTRODUCGIÓN*

Describimos y explicamos aquí la historia americana del originalmente honorífico su merced, que se emplea en nuestros días en América (Colombia, Ecuador, Perú y República Dominicana) como forma (pronominal) de tratamiento coloquial. A través del análisis de un corpus de casi un millar de datos lingüísticos directamente extraídos de documentos de archivo, describimos los contextos de empleo y la sintaxis de su merced en una diacronía amplia (cuatro siglos) y en una diatopía extensa (el territorio americano). De esta manera, aportamos a la comprensión de cómo aquella forma, creada y empleada por el estamento noble en la Península Ibérica -conjuntamente con vuestra merced, su señoría, vuestra señorí, su excelencia, vuestra excelencia...- se incorporó a la comunicación cotidiana de millones de hablantes del español en América. Ofrecemos aquí un panorama de la totalidad de los usos de su merced, concentrando la atención en el proceso diacrónico, sin limitar nuestro estudio a aquellos que pudieran considerarse formas de tratamiento y, por tanto, antecedentes de los actuales empleos pronominales en el tratamiento coloquial.

Hasta ahora tratados indistintamente, las dos especies de su merced que hemos identificado se diferencian por su posibilidad de empleo o no como forma de tratamiento y por su construcción sintáctica, que analizaremos más adelante en detalle. La investigación realizada nos ha permitido descubrir dos vías de desarrollo de su merced en América en dos contextos comunicativos bien diferenciados, que hemos denominado contexto institucional y contexto interpersonal. Ponemos en relación estas dos derivaciones de un cambio lingüístico con dos tradiciones discursivas claramente diferenciables: la conversacional, propia de cartas y de la reproducción de discurso directo, y la tradición discursiva institucional, que se manifiesta en documentos administrativos y jurídicos por medio de distintos géneros (toma de declaraciones, certificaciones, juramentos, atestados, entre otros). En esta última tradición, su merced desaparece, en tanto que pervive en la primera. Nuestro trabajo articula explicacio-

* Queremos agradecer los comentarios de los lectores anónimos -muy especialmente, la sugerencia del esclarecedor artículo de López SERENA (2011) - que nos han permitido ser más explícitas y claras en relación con el concepto de tradiciones discursivas. 
nes hasta ahora fragmentarias al integrar resultados de investigaciones sobre diacronías parciales y al ensamblar estudios basados en distintas fuentes.

En el siguiente apartado nos detendremos en algunos conceptos básicos, como paso previo a un somero estado de la cuestión. En "Corpus y análisis" describimos los materiales utilizados y el método de análisis empleado. Luego de ello, en dos apartados extensos ("Diacronía de su merced en América" y "Sintaxis de su merced") presentamos los datos encontrados, analizados según parámetros semánticos y pragmáticos y según la sintaxis de la construcción, respectivamente. Sigue a estos dos apartados otro de título "Discusión", en que interpretamos los datos obtenidos y realizamos observaciones teóricas y metodológicas. Por último, el artículo termina con algunas consideraciones finales y propuestas de trabajo para el futuro.

\section{Algunos CONCEPTOS BÁSICOS}

El primero de los conceptos en que nos detendremos un momento es el de tradición discursiva, ya mencionado en el apartado anterior. Según la caracterización de Schrott (2017, p. 26), puede concebirse como "un saber cultural que sirve como hilo conductor para la interacción lingüística en situaciones concretas". Las características de este saber cultural, así como la definición y la ubicación teórica del concepto de tradiciones discursivas, son desgranados por López Serena (2011), de quien retomamos las siguientes dos cuestiones. La primera de ellas es la definición de una tradición discursiva como "tipo de patrón de construcción de discurso intermedio entre el género [empleado aquí en el sentido clásico bajtiniano] y las realizaciones discursivas efectivas" (López Serena 2011, p. 76). Esta definición se apoya en la también clásica distinción de Coseriu (1967) entre sistema y norma, de forma tal que el género se inscribiría en el sistema como lo hacen las tradiciones discursivas en la norma. Señala López Serena:

De acuerdo con todo esto, si concebimos... la categoría tradición discursiva como análoga a la de norma, por contraste con el concepto de género como equivalente al de sistema, las tradiciones discursivas, en tanto que conjuntos específicos de normas para construir e interpretar textos particulares en el marco de deter- 
minados géneros, quedarían definidas, única y específicamente, como subdeterminaciones históricas de los géneros $(i d$.$) .$

La segunda cuestión es su insistencia en el hecho de que los parámetros que regulan las modalidades concepcionales (oralidad y escrituralidad concepcional), por su condición universal, atraviesan los géneros y también, por cierto, las tradiciones discursivas, aunque los primeros sean situacionales, y las segundas (y terceras), textuales. La variación concepcional, más que con lo textual o lo discursivo, se relaciona con "hablar" en diferentes tipos de circunstancias, en entramados situacionales que se ubican en un continuo entre la máxima inmediatez o máxima distancia comunicativas (López Serena 2011, p. 80).

Hechas estas precisiones, resta por aclarar algunos términos en relación con las denominaciones seleccionadas para las tradiciones discursivas identificadas. Hemos escogido la etiqueta tradición discursiva institucional para dar cuenta de las formas de construcción discursiva que, además de incluir su merced, comparten vínculos con diversos géneros de circulación propia de lo jurídico o de lo administrativo. Desechamos la etiqueta diplomática empleada por Koch (2008) porque el término resulta algo ambiguo por aludir también a las regulaciones de las relaciones internacionales; porque para Koch (2008, p. 64) comprende además géneros epistolares; y porque documento -diplomática 'estudio de los documentos antiguos'- se emplea aquí como hiperónimo de todos los textos consultados en los corpus. Asimismo, hemos escogido el término interpersonal, por falta de otro mejor, para nombrar la otra tradición discursiva ${ }^{1}$ y designar unas manifestaciones que parecen estar culturalmente guiadas por la inmediatez comunicativa, y hemos descartado los términos dialogal o conversacional por emplearse en la caracterización de secuencias textuales (Adam 1992). Con el término seleccionado, y considerando que en normatividad histórica una misma tradición discursiva puede formar parte de la técnica constructiva de diferentes

1 Alguien podría cuestionar si esta segunda derivación es, efectivamente, una tradición discursiva o si se trata de los comienzos de un proceso de difusión en una comunidad idiomática. Esta discusión podría reservarse para un trabajo de mayor espesor teórico, pues requeriría de más datos históricos fiables que con los que se cuenta en la actualidad. 
géneros, buscamos cubrir tanto el género epistolar como el del diálogo cara a cara².

Por lo demás, entendemos aquí por formas de tratamiento la codificación lingüística empleada para dirigirse a la segunda persona del discurso, y por formas referenciales, la codificación lingüística mediante la cual se habla acerca de una tercera persona del discurso; éstas pueden compartir con los tratamientos la capacidad de codificar significados normalmente relacionados con ellos, como la actitud, el poder u otros. También empleamos para las formas de dirigirse al alocutario (segunda persona del discurso) la expresión formas alocutivas, y para hablar de una tercera persona, formas delocutivas (Benveniste 1970).

Conceptualizamos ámbito como espacio social y empleamos esta variable con dos valores: la familia y la sociedad, tal como estos términos se utilizan en el español corriente. En cuanto a la noción de poder, ésta es conocida y ampliamente retomada en los estudios sobre tratamientos a partir del trabajo de Brown y Gilman (1960), quienes entienden por poder la posibilidad de influencia o control sobre el comportamiento del otro (Brown \& Gilman 1960, p. 255). Proponemos que hay actitud cuando se expresa el talante del locutor hacia el alocutario, actitud que puede ser deferencial, o sea, de amabilidad hacia el interlocutor, pero que no implica ponerse en una posición de menos poder que él, o reverencial, es decir, de respeto o reverencia, cuando el locutor revela inequívocamente que tiene menos poder que el alocutario (Bertolotti 2015, pp. 21-22). Esta última actitud suele ir acompañada de expresiones humiliativas para el propio locutor.

Como es bien conocido, su merced surge a fines de la Edad Media como delocutivo y actualmente se usa como alocutivo. El reempleo de formas originalmente de tercera persona o referenciales para la alocución es normal en las lenguas, como en el caso del sueco, italiano o portugués. Esta tercera persona puede ser una forma pronominal -como fue en español él/ ella o, hasta el siglo pasado, han/ hon ('él/ ella') en sueco- o una forma nominal -como vuestra merced en español o senhor ('usted') en portugués. También es usual el empleo del plural para el singular como tratamiento; por ejemplo, el vous ('usted -es') en francés y el $n i$ ('usted -es') en sueco. En las lenguas romances, varias

${ }^{2}$ La oposición entre institucional e interpersonal no significa, por cierto, que entendamos que la comunicación interpersonal, en sentido literal, no está presente en toda la actividad lingüística. 
formas originalmente utilizadas como referenciales corteses, como es el caso de su merced, pasaron a emplearse como formas de tratamiento, pero es éste el único caso en español de un referencial; insistimos: "de un referencial", pues por ello se distingue de vuestra merced ${ }^{3}$, que llega a un estadio de pronominalización. Su merced forma parte del conjunto de los tratamientos nominales que surgen en relación con el cambio semántico del pronombre vos. Se trata de un honorifico, esto es, una categoría específica dentro de los tratamientos sociales (de parentesco, generales, ocupacionales, de amistad, cordialidad y afecto, honoríficos; cf. Fontanella 1999, p. 1419, quien se basa en Rigatuso 1994, p. 21). Más aún que otros, los tratamientos sociales honoríficos implican a quien los da y a quien los recibe, ya que se crean como formas destinadas a nombrar a integrantes de un grupo con poder social, tal como lo era el estamento noble. De ello se deduce que su empleo tendrá lugar entre pares que integran este grupo (actitud deferencial) o entre "inferiores" que hayan de referirse a miembros de la nobleza, tanto dentro como fuera del ámbito familiar, y, por lo tanto, en situaciones en que el locutor detenta menor poderío (actitud reverencial).

Desde el punto de vista de su composición, su merced es un tratamiento con posesivo; en este tipo, los honoríficos se caracterizan por constituirse con posesivos de segunda o de tercera persona combinados con un sustantivo abstracto. Este sustantivo da cuenta de alguna cualidad de la persona a la que se dirige o a la que se refiere el tratamiento honorífico; por ejemplo, su/ vuestra excelencia, su/vuestra merced, su/vuestra paternidad. En el caso que nos ocupa, por ser originalmente referencial, el posesivo es de tercera persona, y el sustantivo merced, una metonimia de poder, significa que el aludido por su ("principal" o "señor") tiene la cualidad de hacer gracias o dádivas a sus "vasallos, criados u otras personas", como recoge Covarrubias (1611; cf. Bertolotti 2017, pp. 309-312).

\section{EsTADO DE LA CUESTIÓN}

Podemos identificar cuatro tópicos en los estudios sobre la forma su merced en español: el origen americano o europeo de los

${ }^{3}$ Esta afirmación no sería válida si consideráramos el sintagma nominal la vuestra merced un referencial luego idiomatizado. 
usos alocutivos y su diacronía; su gramaticalización; su presencia en hablas afrohispanas; estudios sobre usos actuales.

Tradicionalmente, su merced alocutivo, primer tópico, se ha concebido como desarrollo americano. En un trabajo reciente, Calderón Campos y García Godoy (en prensa) señalan antecedentes europeos en estos usos que caracterizan como "duales", en el sentido de que como tratamiento la forma puede significar tanto 'respeto' como 'intimidad'. Proponen cuatro estadios en la evolución de su merced ( su merced $3^{\mathrm{a}}$ persona $>$ su merced $2^{\mathrm{a}}$ persona en ámbito social $>$ su merced $2^{\mathrm{a}}$ persona en ámbito familiar $>$ su merced $2^{\mathrm{a}}$ persona con intimidad máxima). En el español europeo, García Godoy (2008) analiza el empleo de su merced en el siglo xix en Andalucía, documenta su carácter de tratamiento asimétrico y explica su uso con base en la pérdida de valores de formalidad y distancia de la forma gramaticalizada usted en este siglo. En términos sociolingüísticos, señala que su uso se extendía preferentemente entre la clase artesanal andaluza.

Los trabajos mencionados son quizás las únicas excepciones, ya que se ocupan del origen preamericano de su merced, más allá de lo dicho en los trabajos clásicos de Lapesa (2000 [1970]) y Keniston (1937). Lapesa (2000, p. 321), quien postula el origen delocutivo de su merced, esto es, una forma referencial, documenta su pasaje a una forma alocutiva en los siglos XVI y XVII. Entiende que hay una especialización de su merced en el trato de inferiores a superiores, cual de criado a señor, y relaciona este hecho, tal como lo hará García Godoy (2008), con la generalización de usted. Keniston (1937, §4.437, p. 45) señala que en el frecuente empleo de su merced como equivalente del pronombre de tercera persona podría residir el origen de su movimiento hacia la segunda persona, contexto sintáctico que habilitaría entonces el pasaje de delocución a alocución. Hay igualmente trabajos en que se considera su merced históricamente, se discute su devenir y se aportan ejemplos americanos (Carrera de la Red y Álvarez Muro 2004; Granda 2007; Obediente Sosa 2009; Rigatuso 2009). Granda (2007, p. 166), por ejemplo, postula dos períodos cronológicos, uno que se caracteriza "por la existencia, de modo exclusivo, de la dimensión vertical, asimétrica... en tanto que en el segundo (posterior) coexisten las dimensiones vertical, asimétrica, y horizontal, simétrica, del mismo".

En cuanto a la gramaticalización de su merced, segundo tópico, se ha señalado que es una de las varias formas honoríficas surgidas al final de la Edad Media, una entre otras con su mis- 
ma estructura, es decir, un posesivo y un sustantivo abstracto de cualidad. El español contó entonces con dos series: vuestra excelencia, vuestra señoría, vuestra merced.../ su excelencia, su señoría, su merced. Todas estas formas, en mayor o menor medida, entrarán en procesos de gramaticalización, fenómeno estudiado por varios especialistas (Koch 2008; De Jonge y Nieuwenhuijsen 2009; García Godoy 2012; Sáez 2013, 2014; Bertolotti 2017, entre otros).

En cuanto a su presencia en hablas afrohispanas, tercer tópico, Álvarez López y Bertolotti (2013), a partir del análisis de datos literarios, confirman la relación ya apuntada entre el uso de la forma su merced en América en el siglo xix y hablantes de origen africano o hablantes insertos en relaciones fuertemente asimétricas. Aunque con escasa evidencia de datos, tal relación ya se había formulado en estudios anteriores (Sologuren 1954, apud Hummel 2010; Pérez Guerra 1988 y 1989; Granda 2005 y 2007; Obediente Sosa 2009 y 2010). Algunos autores como Uber (1985, pp. 277-278), Granda (2005, p. 247) y Mestre Moreno (2010, p. 1036) señalan además que es una forma de tratamiento asociada a lo rural americano, lo cual no es incompatible con el empleo que de ella hacen hablantes africanos o descendientes de africanos.

En lo concerniente a los usos actuales, hay bibliografía abundante sobre la presencia de su merced en el español de América, especialmente en el caso de Colombia (Uber 1985; Ruíz Morales 1987; Montes Giraldo 2000; Bartens 2003; Placencia 2010; Mestre Moreno 2010). En un estudio sociolingüístico, Cepeda Ruiz (2014) documenta y analiza su merced como forma de respeto y de confianza en Bogotá. También señala el carácter pronominal de su merced y que su empleo "dentro de la familia [es] frecuente con personas que ostentan autoridad como padres, tíos, abuelos y suegros. Y fuera de ella es usado con personas mayores" (p. 203). Asimismo, hay estudios y referencias al empleo de su merced en los actuales países de Ecuador (Placencia 2010), Perú (Hummel 2010) y República Dominicana (Pérez Guerra 1988 y 1989).

Analizados estos antecedentes, surge la necesidad de $a$ ) dar una explicación totalizadora de usos alocutivos y delocutivos con base en un número de datos mayor que los analizados en general hasta ahora; $b$ ) integrar los estudios parciales sobre hablas afrohispanas representadas en fuentes literarias con los estudios realizados a partir de documentos de archivo; $c$ ) sope- 
sar la pertinencia de las frecuentes afirmaciones con respecto al carácter rural, afrohispano y/o asimétrico de la forma; $d$ ) describir la posible existencia de estadios de gramaticalización que puedan ponerse en relación con los usos pronominales actuales. Nos ocuparemos en este artículo de las tres primeras cuestiones y esbozaremos algunos avances sobre la cuarta.

\section{CORPUS Y ANÁLISIS}

Esta investigación se basa en el Corpus Diacrónico y Diatópico del Español de América (CORDIAM), que contiene tres subcorpus. Nos concentramos exclusivamente en los documentos tomados de archivo (CORDIAM-Documentos) y excluiremos los subcorpus de literatura y de prensa. CORDIAM-Documentos incluye testimonios escritos en todos los actuales países americanos entre los siglos XVI y XIX. Al momento de concluir este trabajo, el corpus contaba con 4466 documentos de archivo que fueron objeto de nuestras búsquedas (aproximadamente 4 millones de palabras). Realizamos las siguientes búsquedas: su merçed, su merçe, su meiçe, sumerçed, sumerçe con indiferencia a los diacríticos. Encontramos 983 concordancias distribuidas en 316 documentos de 15 actuales países latinoamericanos hispanohablantes $^{4}$, que fueron nuestro universo de análisis. Según la tipología documental establecida en CORDIAM ${ }^{5}$ (documentos administrativos, cronísticos, entre particulares: cartas y otros, jurídicos), los casos se distribuyen de la siguiente forma: $22 \%$ (219/983) en administrativos, 63\% (622/983) en jurídicos y $14 \%$ (142/983) en documentos entre particulares.

${ }^{4}$ No encontramos datos de su merced para los siguientes países incluidos en CoRDIAM: Belice, Guayana, Jamaica, Nicaragua, Panamá, Paraguay, Puerto Rico, República Dominicana, Trinidad y Tobago. Recordemos que la no ocurrencia no es prueba de no existencia.

${ }_{5}^{5}$ El CORDIAM cuenta con una tipología textual para los documentos extraídos de archivos. Cada documento se adscribe a uno de los siguientes cuatro tipos textuales: administrativo, cronístico, documentos entre particulares (cartas y otros) y jurídicos (cf. CORDIAM, Tipos textuales, en http:/ /www. cordiam.org/doc/documentos-tipos-textuales.html). El tipo textual administrativo incluye instrucciones, inventarios, testamentos, órdenes, entre otros géneros; el jurídico, interrogatorios, querellas civiles o criminales, testimonios, sumarias, entre otros; el correspondiente a documentos entre particulares (cartas y otros) -el tercer tipo en que aparecen casos de su merced-, cartas, billetes y notitas como géneros principales. 
Generamos una base de datos en la cual procesamos las concordancias obtenidas, tomando en cuenta 8 variables: 1) el emisor de la forma su merced; 2) su empleo como tratamiento (en los casos en que era sustituible por un pronombre de $2^{\mathrm{a}}$ en el contexto) o como expresión referencial (en los casos en que era sustituible por un pronombre de $3^{\mathrm{a}}$ en el contexto); 3) su carácter honorífico o no, entendiendo por honorífico aquellas expresiones que dan cuenta de una actitud reverencial hacia el interlocutor; 4) la distancia social entre interlocutores, que solamente codificamos en el caso de los usos de tratamiento; 5) el poder como posibilidad de control o influencia en el comportamiento del otro, codificado como más, menos o igual poder; 6) el ámbito familiar o social; 7) la función sintáctica de la forma (sujeto, objeto, complemento, incluidas en éstos todas las formas de complementación propiamente dicha, así como también las de adjuntos, tanto de nombres como de verbos y vocativos); 8) la deixis de su merced. En el caso de que su merced tuviera un sintagma nominal (SN) en aposición incluimos el SN correspondiente en la base de datos.

Además de analizar la concordancia obtenida a través de la búsqueda automática, estudiamos detalladamente cada contexto, y en muchos casos, todo el documento, para una mejor comprensión discursiva y textual. Este análisis fue especialmente exhaustivo en el caso de una serie de ejemplos ambiguos, que consideramos adecuado consignar como tales para ofrecer al lector las posibles interpretaciones.

Con objetivos de contraste de la información obtenida, realizamos consultas en el CORDE, a partir del cual verificamos que en los contextos no literarios americanos, aunque con número menor de ocurrencias (332 casos en 70 documentos), se encuentran los mismos hechos lingüísticos y las mismas tendencias que figuraban ya en la documentación del CORDIAM. Por esta razón, no desarrollamos aquí los resultados que arrojó el análisis de los datos del CORDE.

\section{DiACronía DE SU MERCED EN AMÉriCA}

En este apartado presentamos, ordenados por siglo, los datos obtenidos de la búsqueda en el corpus, con una cuantificación descriptiva de dos variables: los tipos de textos en que se descubren los casos de su merced y el carácter alocutivo o delocutivo. 
Al final de cada sección, incluimos un cuadro sinóptico con estos datos. En términos generales, podemos afirmar que los ejemplos se encuentran, mayoritariamente, en textos escritos por hombres, como es de esperar para los siglos que analizamos. Destacamos la presencia, también esperable para la época, de algunos escritores de origen español que, al igual que los no españoles, formaban parte de la colectividad comunicativa americana.

Siglo XVI

Las primeras formas documentadas de su merced en América halladas en nuestro corpus datan de 1518 y se encuentran en un texto en que Diego Velázquez, gobernador y capitán general de Cuba, pide que se le dé traslado de una instrucción que Hernán Cortés había entregado:

el qual dicho hernando cortés llevó consigo la dicha ynstruçión al tienpo quese partió con el dicho Cargo de la qual quedó vn Registro en esta dicha çiudad e por que al presente él tenía neçesidad de vn treslado o dos o más de la dicha ynstruçión e Capítulos della para la enbiar o presentar a donde su merçed quisyese o por bien toviese por tanto que pedía e pidió al dicho señor al $c a$ ld $e$ mandase sacar de la dicha ynstruçió $n$ vn treslado o dos o más los quales en pública forma signados de mí el dicho escriuano e firmados del no $n$ bre del dicho señor alcald $e$ se los mandase dar para los presentar segund e Como por su merçed hera dicho (año 1518, Cuba, administrativo, CORDIAM).

A lo largo de todo este siglo, se encuentran ocurrencias de su merced (268) en 124 documentos escritos entre los años 1518 y 1597; pertenecen al tipo textual jurídico $(82 / 268)$, al tipo textual administrativo $(89 / 268)$ o al tipo textual de documentos entre particulares $(97 / 268)$ y aparecen en los siguientes actuales países americanos: Colombia, Honduras, México, Uruguay y Venezuela.

El análisis del carácter del tratamiento (alocutivo) o referencial (delocutivo) de cada una de las concordancias obtenidas arroja que el 99\% (266/268) se conforma de usos referenciales, en tanto que sólo el $1 \%$ (2/268), de tratamientos. Los casos referenciales figuran, mayoritariamente, en textos administrati- 
vos y jurídicos, aunque también en documentos entre particulares que dan cuenta de relaciones interpersonales. En los usos institucionales referenciales de su merced, este sintagma refiere o correfiere siempre a una autoridad instituida como, por ejemplo, "señor gobernador", "señor teniente", "dicho capitán”:

fue por mandado de su merçed a la florida y punta de santa elena con çierta conduta e ynstruiçión de su merçed con vna carta Real de su magestad y que él fue e hizo todo su dever en el caso por tanto que él hazía y hizo presentaçión de las diligençias que en ello avía hecho y entregó a su merçed del dicho señor governador la dicha Real carta que avía Resçebido (año 1564, Cuba, administrativo, CORDIAM).

En este contexto institucional, quienes escriben los documentos son casi en su totalidad personas con cierta función en los procesos administrativos o de justicia, sin capacidad para tomar decisiones, ya que presentan los hechos ante la autoridad correspondiente (a la cual se refieren como su merced y que es capaz de hacer merced, es decir, 'hacer una concesión o un favor'), quien finalmente decidirá respecto del caso particular. En este sentido, hay diferencia de poder, entre el hablante/ escribiente (quien detenta menos poder) y el destinatario de $s u$ merced (quien detenta más poder). El uso de su merced presenta en este siglo una clara especialización ocupacional y refleja la distancia social o institucional, que entendemos como reverencial. El escritor suele disminuirse ante el destinatario, con humiliativos del tipo "humilde servidor".

En los usos interpersonales, su merced se halla casi exclusivamente en cartas en que el sintagma se refiere a miembros de la familia o del entorno social del o de los destinatarios. A modo de ejemplo, en la siguiente carta, quien escribe se refiere con su merced a alguien que cuidó a su esposa:

a mi señor antón sánchez beso las manos mill vezes y que dios le pague la merced que su merced me a hecho en tener el cuydado y cargo que de vos señora a tenido y tiene que dándome dios salud yo se lo serviré (año 1569, México, carta, CORDIAM).

Entre otros ejemplos del mismo uso en cartas, encontramos que en dos de ellas se hace referencia a mujeres, en uno de los casos a una conocida y en otro a la madre de quien escri- 
be, mediante su merced (año 1570, Perú, carta, CoRDIAM). Documentamos así usos familiares ya desde este siglo, aunque no se emplean como tratamientos. Sólo el $1 \%$ de su merced como tratamiento se presenta en esta tradición discursiva interpersonal, que ejemplificamos a continuación. En carta, Alonso del Pozo, chantre, responde al señor Francisco Patino del Pozo acerca de una donación; se dirige a él como muy magnífico señor de la siguiente manera:

recebí vna de vm fecha a v́ltimo de hebrero del año de setenta creo fue ierro porque las demás que con ella venían dezía la fecha del año de setenta y vno sea como fuere yo reçebí grandísimo contento y plazer y muy notable merced por lo qual beso a vm las manos y a la señora mi hermana y prima ana de tapia que me dize casó con su merced holgara mucho hallarme allá aquel tiempo para mejor gozar de seruirla (año 1574, Nicaragua, carta, CORDIAM).

Podría cuestionarse el carácter alocutivo de este ejemplo si su merced se leyera como delocutivo; en tal caso, el referente tendría que ser alguien no identificado en esta carta y casado con Ana de Tapia.

En otro caso, para seguir con nuestra ejemplificación, Gonzalo Hernández se queja a Juan Francisco (cuyo apellido desconocemos) de que un sobrino suyo le quitó dinero y lo amenazó. Hernández trata a Juan Francisco de muy magnífico señor, y en un pasaje escribe:

moryré mañana y ny io ny mis erederos lo berán escrybo ésta para que pues esta pobreza que tengo es de my mujer y de my hija no se les pierda por my býa que conforme a nuestra memorya que ba con ésta se merezca... probysyón de su merced como la pido (año 1582, Ecuador, carta, CORDIAM).

Es posible interpretar, a partir de la lectura de toda la carta, que su merced es el destinatario, pero también se puede interpretar que se está haciendo referencia a una eventual autoridad a la cual el destinatario tendría que recurrir para satisfacer el pedido de Gonzalo Hernández. Como señalamos más arriba, dejamos explícitas lecturas alternativas en que su merced no tendría empleo alocutivo, sino delocutivo, no solamente porque corresponde hacerlo de esta manera, sino también porque entendemos que así como la lectura es ambigua en la actuali- 
dad, puede haberlo sido también en épocas pasadas para quienes leyeran u oyeran la lectura de la carta.

Como ilustra el Cuadro 1, las formas delocutivas (referencial) y alocutivas (tratamiento) de su merced en la tradición discursiva interpersonal pueden emplearse para referir o tratar, tanto en ámbitos sociales (conocidos) como familiares, a personas consideradas (magníficos) señores o señoras. En ambos casos interpretamos que el uso tiene un sentido deferencial (D), pues se intenta mostrar que el remitente se refiere o trata a la persona a quien se dirige de manera respetuosa por pertenecer a determinado grupo (el mismo que integra el remitente, por lo cual tiene igual poder $[=\mathrm{P}]$ que su destinatario). Este uso de $s u$ merced se distingue en este rasgo de los usos que se observan en la tradición institucional, en los que el carácter reverencial (R) de la forma se hace evidente. En tales casos, un individuo con menos poder (-P) se dirige al representante de una autoridad.

\section{CuAdro 1}

Siglo XVI: usos de su merced

\begin{tabular}{lll}
\hline & Referencial & Tratamiento \\
& $99 \%(266 / 268)$ & $1 \%(2 / 268)$ \\
\hline TD institucional & $\mathrm{R},-\mathrm{P}$, autoridades & - \\
TD interpersonal & $\mathrm{D},=\mathrm{P}$, & $\mathrm{D},=\mathrm{P}$, \\
& familiares, conocidos & familiares, conocidos \\
\hline
\end{tabular}

Nota: $\mathrm{TD}$ = tradición discursiva; $\mathrm{R}$ = reverencial; $\mathrm{D}=$ deferencial; $\mathrm{P}$ = poder.

Siglo XVII

La extracción de datos del siglo XVII arroja 187 ocurrencias de su merced. Se encuentran en 72 documentos escritos entre 1601 y 1698 que pertenecen a los siguientes tipos textuales: jurídico $(127 / 187)$, administrativo $(53 / 187)$ y documentos entre particulares $(7 / 187)$. Los textos fueron escritos en los siguientes actuales países: Bolivia, Chile, Colombia, Costa Rica, Cuba, Ecuador, EE. UU., Guatemala, Honduras, México, Perú, Salvador y Venezuela.

En casi todos los casos (184/187), se trata de lo que hemos llamado su merced institucional. Tal como en el siglo XvI, la deixis se realiza a cargos, aunque el repertorio de éstos parece 
ser más amplio que en el siglo anterior. Se suman a los cargos ya mencionados los de vicario, teniente de capitán general, señor licenciado, señor visitador, entre otros. La actitud es siempre reverencial, y en continuidad con el siglo anterior, no se descubren tratamientos entre las formas de su merced institucional.

Encontramos tres casos (en 187) de su merced interpersonal. Se trata de usos en que, por medio de carta, se hace referencia a conocidos: a un "señor" (1640, México), a "mi señora doña Ana” (1642, Perú) y "a don Pedro Cortés" (1696, Chile). La lectura íntegra de los textos en que se encuentran las formas permite afirmar que la actitud de los locutores es deferencial. Ejemplificamos con un pasaje de cierta carta en que Francisco del Barco trata cuestiones personales y patrimoniales. En ella, se refiere al "señor don Barttolomé" con su merced:

Y, en quantto a los mill y quattroçienttos ducados de mayorazgo de Pila, que vuestra merced diçe sacó el señor Ortuño del Barco, no los deue el señor don Barttolomé pues no los caussó su merçed porque todos los vienes que diçe por su ttestamentto dexó no heran suyos sino dotados ya a su hijo (año 1640, México, carta, CORDIAM).

Los usos interpersonales referenciales muestran actitud deferencial y revelan la filiación a un grupo social que se reconocía recíprocamente en las cortesías. El CORDIAM no cuenta con registros para el siglo XVII de formas alocutivas en situaciones de comunicación interpersonal. El Cuadro 2 sintetiza lo señalado:

\section{CuAdro 2}

Siglo XVII: usos de su merced

\begin{tabular}{lll}
\hline & Referencial & Tratamiento \\
& $100 \%(187 / 187)$ & $0 \%(0 / 187)$ \\
\hline TD institucional & $\mathrm{R},-\mathrm{P}$, autoridades & - \\
TD interpersonal & $\mathrm{D},=\mathrm{P}$, & - \\
& familiares, conocidos & \\
\hline
\end{tabular}

Nota: $\mathrm{TD}=$ tradición discursiva $; \mathrm{R}=$ reverencial $; \mathrm{D}=$ deferencial $; \mathrm{P}=$ poder. 
Siglo XVIII

El siglo XVIII representa una veta especialmente valiosa para el análisis del devenir de su merced, toda vez que se encuentran 481 ocurrencias en 107 documentos escritos a lo largo de todo este siglo. Los textos pertenecen al tipo textual jurídico (383/481), administrativo (72/481) o documentos entre particulares (26/481) y se llevaron a cabo en los siguientes actuales países: Argentina, Bolivia, Chile, Colombia, Costa Rica, EE. UU., Guatemala, Honduras, México, Perú, Salvador, Uruguay y Venezuela.

Contrariamente a lo que constatamos para el siglo XVII, en el XVIII hallamos usos de su merced como tratamiento que corresponden a un $5 \%(24 / 481)$ del total en ese siglo. Las restantes concordancias $(95 \%, 457 / 481)$ son empleos referenciales. En estos usos delocutivos, tal como sucede en los siglos anteriores, su merced se especializa mayoritariamente en la referencia o correferencia a autoridades instituidas. En cuanto a las posibles formas alocutivas (24/481), éstas se localizaron en dos textos de tipo administrativo y en dos documentos entre particulares. Por primera vez, podríamos estar frente a alocutivos en contextos institucionales, aunque todos ellos tienen más de una interpretación posible -retomaremos la cuestión de la ambigüedad de los ejemplos y los tipos de fuente en el apartado correspondiente a la "Discusión". Son casos (5/24) en que se puede interpretar que un capitán, un gobernador, un cura y un capellán tratan con la forma su merced a un gobernador, a un señor general, a un vuestra paternidad, a un su ilustrísima, respectivamente. Todo lo dicho se resume infra en el Cuadro 3.

En el siguiente ejemplo, en que un capellán se ocupa de cuestiones relacionadas con el ornamento de una iglesia, entendemos que su merced se emplea como tratamiento, aunque no es posible descartar la interpretación de que se alude a una tercera persona:

y más señor quando aquella yglecia de galapa tiene los hornamentos sullos y dieron los enComenderos y los que alquirió de la yglecia distinguida del pueblo de paluato y los que su Merced le enbió (año 1745, Colombia, carta, CORDIAM).

Otros dos de estos ejemplos que suscitan la ambigüedad aparecen en una carta (Estados Unidos, 1706) en que se pue- 
de interpretar o bien que la fórmula se desempeña como correferente con vuestra paternidad -el destinatario-, o bien que se trata de una correferencia a personas que detentan cargos ya mencionadas en el contexto de la carta. Éstas podrían ser, en un caso, nuestro amigo el señor sargento mayor Don Manuel de Iriarte o el general Juan Páez, en el otro. Semejantes a estos casos son las ocurrencias encontradas en las dos cartas restantes (México, 1767 y Uruguay, 1774). En la del actual Uruguay, se trata de un remitente que muestra rasgos de hipercorrección, mientras que la expresión su merced aparece en aposición a vuestra señoría. Interpretamos de ello que, por lo menos para este remitente, el sintagma su merced no suponía en sí mismo una expresión honorífica, ya que se ve en la obligación de agregar vuestra señoría, lo cual es síntoma del cambio semántico que está sufriendo su merced en la época.

En cinco ocasiones aparecen empleos delocutivos en contexto interpersonal, que no refieren a autoridades instituidas, sino a miembros de la familia pertenecientes a una generación de mayor poder (madre o padre, con lo que se da continuidad a usos en contexto familiar, ya esbozados en el siglo XVI). Abajo reproducimos parte de una de las cartas a que nos referimos (México, 1710 y 1791; Perú, 1721; Colombia 1759; Argentina, 1762). En ella, Antonio de Vivero Suárez y Zúñiga, que escribe a un amigo y señor, habla de la salud de su madre, a quien luego se refiere con el sintagma su merced:

La salud de mi señora madre deseo más que la mía y sólo ttengo el senttimientto de mi mala correspondencia, mas no me faltta el conocimientto de las muchas obligaciones que deuo a su merced y así le suplico me hauise de [su] salud y de la de vuestra merced a quien guarde Dios muchos años que deseo. México, honce de xulio de mil settecienttos y diez (año 1710, México, carta, CORDIAM).

Los empleos de su merced como tratamiento en contextos interpersonales se presentan siempre entre miembros de una misma familia en relaciones en que los locutores (hijo/ hija y nuera) detentan menos poder que el alocutario (padre o suegro). El más dramático de los casos se ofrece en una declaración en que, luego del testimonio de un padre acusado de violación, se da la palabra a la hija, quien, dirigiéndose directamente a su padre, dice: "Tayta, cómo puede decir que es falso, cuando 
su merced sabe que pasó como yo dije" (año 1795, Venezuela, jurídico, CORDIAM; nótese que la niña se dirige al padre con el vocativo familiar "taita"). Los otros usos de su merced en contexto familiar aparecen todos en Argentina, en cartas escritas a un padre y suegro por su hijo y su nuera, respectivamente. En ellas, la temática central es la necesidad de los que escriben de que el padre/ suegro les preste dinero. En el siguiente fragmento, podemos ver uno de estos usos de su merced:

Padre y Señor Don Domingo de Basavilbaso Padre y muy Señor mío, por la adjunta Esquela reconocerá Su merced el triste estado en que me hallo, sin que para mover â más piedad haga relación de otras muchas necesidades que por las justas instancias de mayores acrehedores tengo (año 1762, Argentina, carta, CORDIAM).

Cabe consignar un dato que podría ser relevante para interpretar este empleo de su merced: el señor Basabilbaso, a quien se dirigen hijo y nuera, detentaba el cargo de alcalde. Esto nos lleva a preguntarnos si el uso de su merced es meramente una forma de respeto para dirigirse a alguien de una generación mayor, en cuyo caso lo consideraríamos deferencial por destinarse a un individuo que es parte del mismo grupo, o si se trata de un uso reverencial o de especialización ocupacional, al escoger su merced no por su condición de padre/ suegro, sino por su condición de alcalde.

\section{CuAdro 3}

Siglo XVIII: usos de su merced

\begin{tabular}{lll}
\hline & $\begin{array}{l}\text { Referencial } \\
95 \%(457 / 481)\end{array}$ & $\begin{array}{l}\text { Tratamiento } \\
5 \%(24 / 481)\end{array}$ \\
\hline TD institucional & $\mathrm{R},-\mathrm{P}$, autoridades & $\begin{array}{l}\mathrm{R},-\mathrm{P}, \text { autoridades y cंcono- } \\
\text { cidos con autoridad? (Éstos } \\
\text { son los casos ambiguos). }\end{array}$ \\
& & $\mathrm{D},-\mathrm{P}$, \\
TD interpersonal & $\begin{array}{l}\mathrm{D},=\mathrm{P}, \\
\text { familiares, conocidos }\end{array}$ & familiares \\
\hline
\end{tabular}

Nota: $\mathrm{TD}=$ tradición discursiva $; \mathrm{R}=$ reverencial $; \mathrm{D}=$ deferencial $; \mathrm{P}=$ poder. 
Siglo XIX

En el siglo XIX se registran solamente 47 casos de su merced en 13 documentos escritos entre 1800 y 1828 . Éstos se encuentran en textos jurídicos $(30 / 47)$, administrativos $(5 / 47)$ o documentos entre particulares $(12 / 47)$ de los siguientes actuales países: Colombia, Honduras, México, Uruguay y Venezuela.

Como en el siglo XVIII, hallamos sobre todo su merced referencial en la tradición discursiva institucional (en documentos jurídicos y administrativos) con un significado semejante al observado en aquel siglo, esto es, se empleaba su merced mayoritariamente $(35 / 47)$ en referencia o correferencia a cargos de la administración o la justicia civil, criminal y eclesiástica. En la tradición discursiva interpersonal, en una carta escrita por un esclavo (Colombia, 1809), concretamente, encontramos el único ejemplo referencial de su merced en que la deixis no se hace a una autoridad. En cuanto a su merced alocutivo, aparece 12 veces en esta misma carta en que Juan Eugenio Londoño, capataz y esclavo, escribe a "su amo Juan de Dios Londoño y Baños", tratándolo de su merced, para informarle de los trastornos de su hermano Roque, a quien se refiere también como mi amo y su merced:

Saragoza y Julio 20 de 1809. Mi Amo Don Juan de Dios Londoño... participo â Su mersed Cómo mi Amo Don Roque Cada [dí] a está lo mismo, ó a peor, Con desirle á Su mersed, que mi Vida se halla Espuesta; pues temo quando me Coje en el quarto y me mata por que no le Entrego [e]l dinero ó le pega fuego á las Casas... puede Su mersed Verse Con [é]l y Ver lo que pide por ella. Él solo se fue, él solo la Cogió él la trajo o nadie lo aCompañó... Lo sierto del Caso Es mi Amo: Que si Su mersed no da o forma de quan[to] antes el procurar sacarlo puede aber alguna desgrasia, á lo que se agrega que las aciendas se Atrasan, su mersed lo padese, y nosotros también participo todo Esto para el gobierno de Su mersed y el mío, y que no se me atrivuya de negligente Con engañifas lo saqué de la Mesa la Mula... la sana de su mersed la mandé á Sapata por que la hiva matando á Palos por 4. ocaciones le ha [d]ado á prender fuego á la Ramada En el paseo El Macho Retinto tanbién lo mandé A Sapata por que si no, lo mata. Mi Amo manos á la obr[a] lo que se ha de Empeñar que se Venda, procure el mandarle Orden al Alcalde la Parroquia para que se abrese y lo lleben al Ospital Ó Ver si Con el Comandante puede Conseguir un Piquete de soldados y Era lo mejor, por que 
aquí no hay quien se le atreua Contra Su mersed hecha muchas Valerianas y que lo ha de matar, El Negrito Salvador se halla mui malo de un par de incordios á Éste también lo ha Cogido Entre ojos y dice es el alcagüete de Su merced. Boy a dejar la Molienda En Saragosa por hir a lajetar [sic] Trapiches. Espero que Su mersed me Conteste Ésta Con brevedad para mi gobierno y el de su mersed. Deseo la mejor Salud de su mersed, y que Dios nuestro Señor guarde la import[ant]e Vida para Consuelo de Estos sus humildes Esclavos Que SuS Manos Besa Juan Eugenio Londoño \{rub\} (año 1809, Colombia, cartas, CORDIAM).

A diferencia de lo que habíamos encontrado en situaciones interpersonales durante el siglo XVIII, no hay usos en el ámbito familiar, y la actitud del locutor no es deferencial en el siglo xIx. Su merced expresa distancia social y diferencia de poder entre los interlocutores, tal como sintetiza el Cuadro 4. Por consiguiente, podríamos decir que comparte la actitud reverencial que advertimos en los usos de su merced institucional en los siglos anteriores. Los datos encontrados en esta carta van en un mismo sentido que aquellos que aparecen en las representaciones literarias estudiadas por Álvarez y Bertolotti (2013). También Gutiérrez Maté (2013, p. 258) y Obediente Sosa (2009, p. 101) documentan casos similares atribuidos a esclavos en el siglo XVIII.

\section{Cuadro 4}

Siglo XIX: usos de su merced

\begin{tabular}{lll}
\hline & Referencial & Tratamiento \\
& $74 \%(35 / 47)$ & $26 \%(12 / 47)$ \\
\hline TD institucional & $\mathrm{R},-\mathrm{P}$, autoridades & - \\
TD interpersonal & $\mathrm{R},-\mathrm{P}$, & $\mathrm{R},-\mathrm{P}$, \\
& amo & amo \\
\hline
\end{tabular}

Nota: $\mathrm{TD}$ = tradición discursiva; $\mathrm{R}$ = reverencial; $\mathrm{D}=$ deferencial; $\mathrm{P}$ = poder.

SINTAXIS DE SU MERCED

En este apartado describiremos someramente las diferentes estructuras sintácticas que presentan los SN cuyo núcleo es merced, sin entrar, en esta ocasión, en el análisis oracional de 
la forma ${ }^{6}$. A grandes rasgos, puede sostenerse que en los siglos estudiados la sintaxis de su merced institucional se modifica, en tanto que la de su merced interpersonal se mantiene estable durante los cuatro siglos que abarca nuestro corpus, aunque con mayor variación en la ortografía de su representación gráfica (falta de $-\mathrm{d}$ final $\mathrm{y}<\mathrm{s}>$ por $<\mathrm{c}>$ ). Presentamos a continuación los datos de la sintaxis ordenados por siglos.

\section{Siglo XVI}

En el siglo XVI, en los usos de su merced institucional, descubrimos tres tipos de sintagmas -el de su merced con mayor incidencia- en tres tipos textuales. Encontramos un 22\% (58/268) de estructuras del tipo su merced + [de + artículo + sustantivo], es decir, una construcción apositiva del tipo A de B (RAE y ASALE $2009, \S 12.13 d$ ). En todos los casos el sustantivo apuesto es un ocupacional, como gobernador, alcalde o capitán, siempre precedido del término señor o del deíctico dicho, y a veces de ambos, como en "que su merçed del dicho señor tenyente" (año 1551, Venezuela, administrativos, CORDIAM). Todos estos casos figuran en textos administrativos o jurídicos, con excepción de una carta dirigida al mayordomo de Hernán Cortés a propósito de ciertas mercancías enviadas y recibidas, en la que dice: "Escrivióme su merçed del señor liçençiado" (año 1543, México, cartas, CORDIAM). Registramos un caso único en que su merced tiene un sintagma apositivo de nombre propio: "y firmolo de su nombre su merced don Jerónimo de silua ante mî" (año 1581, Bolivia, jurídicos, CORDIAM).

El sintagma su merced interpersonal, en cambio, aparece regularmente sin aposición alguna en el siglo Xvi. Como ya dijimos, los usos interpersonales de su merced en este siglo sólo se presentan en el género epistolar, que se inscribe en el tipo textual correspondiente a los documentos entre particulares.

${ }^{6}$ Cabe anotar que la escritura del sintagma aparece con varias formas en los documentos compulsados: su merced, su mersed, sumercé, su md., su mrd., smd., cuestión en la que no profundizamos en este trabajo. 
Siglo XVII

Los 187 casos de su merced con que contamos en este siglo revelan una sintaxis más diversa en comparación con la del siglo anterior. La estructura más frecuente continúa siendo su merced sin aposición. Sin embargo, encontramos un 39\% de construcciones $(72 / 187)$ con una sintaxis apositiva compleja. Las estructuras registradas son las que siguen, ordenadas por frecuencia decreciente: $a)$ su merced $+[$ dicho $+($ señor $)+$ cargo $]$; $b)$ su merced $+[$ de $+($ artículo $)+($ dicho $)+$ cargo $] ;$ c) su merced $+[$ artículo $+($ señor $)+$ cargo $+($ nombre propio $)]$; d) su merced $+[$ nombre propio + (cargo $)$ ]. Ejemplificamos:

a) Su merced dicho señor oidor, su merced dicho vicario juez eclesiástico $(27 / 187)$.

b) Su merced del dicho juez, su merced del señor visitador, su merced de dicho señor comisario (24/187).

c) Su merced el señor doctor don Nicolás de Adina, su merced el señor comisario, su merced el licenciado Agustín de Torres cura rector (16/187).

d) Su merced don Juan de Urdinsu (5/187).

En tanto que todas las formas descritas en los incisos anteriores aparecen en géneros que tipológicamente pertenecen a lo administrativo o lo jurídico y se inscriben todos ellos en la tradición discursiva institucional, los empleos interpersonales de su merced en el siglo Xvir se presentan con su sintaxis básica, o sea, su merced sin aposición alguna.

\section{Siglo XVIII}

En este siglo, un 25\% (120/481) de las ocurrencias de su merced aparece en construcciones apositivas seguidas de SN similares a los registrados para el siglo XviI. Todas ellas son casos de $s u$ merced institucional, que figura en textos jurídicos y administrativos, como en los ejemplos que siguen:

a) Su merced dicho señor alcalde (32/481).

b) $\mathrm{Su}$ merced de dicho señor alcalde $(4 / 481)$.

c) Su merced el señor juez $(82 / 481)$.

d) Su merced Josep de Gareca escribano público (2/481). 
De la comparación entre los siglos XVII y XVIII resulta llamativa la desaparición casi total de la estructura su merced $+[$ de + (artículo) + (dicho) + cargo], así como el brusco descenso proporcional del deíctico dicho: las estructuras complejas decrecen en proporción con respecto al siglo anterior, así como también decrece su complejidad interna.

Si bien existen posibles tratamientos en su merced institucional, no se registran en ellos aposiciones, con excepción de un único caso en el cual su merced es el sintagma apuesto a vuestra señoría, que ya comentamos en el apartado anterior. Todos estos casos se encuentran en textos administrativos. Tampoco hallamos ocurrencia alguna de aposición con su merced interpersonal, que irrumpe siempre en cartas.

\section{Siglo XIX}

En el siglo XIX, un 9\% (4/47) de las ocurrencias aparece en construcciones apositivas con los siguientes SN en aposición -todos los casos figuran en textos jurídicos-: "el señor comisario del santo oficio", "el señor teniente" y "el señor teniente justicia mayor". Manteniendo la tendencia diacrónica, la frecuencia de las aposiciones sigue bajando en este siglo; todos los casos son del tipo $[\mathrm{AB}]$ y nunca está presente el deíctico dicho en el sintagma. El análisis de los nombres que aparecían en aposición con su merced en siglos anteriores muestra que, si bien los nombres de cargo como alcalde, capitán, gobernador, oidor o vicario se mantienen, nunca están precedidos por el tratamiento su merced: o bien son núcleos, o bien están precedidos por un tratamiento de tipo general como señor.

\section{Discusión}

Hemos identificado el empleo de su merced en dos tradiciones discursivas, institucional e interpersonal, y analizado sus usos a partir de diversas variables (emisor y receptor, ámbito, relaciones de poder y actitud de quien escribe). Hemos explicitado el tipo textual en que se encontró la concordancia y mostrado tanto en qué tipos y géneros textuales como en qué tradición discursiva se inserta su merced. Hemos comprobado, además, que los usos delocutivos constituyen la norma en los cuatro siglos 
analizados y que los usos alocutivos son minoritarios. Hemos documentado la presencia de su merced alocutivo, sobre todo a partir del siglo XVIII, así como empleos de su merced, en ámbitos familiares y de conocidos ya desde el siglo xvi. Podemos señalar, por consiguiente, que su merced empieza a dejar de ser definitivamente reverencial en el siglo XVIII al asumir una especialización ocupacional. Sin embargo, según muestran también los datos, la fórmula recobra su carácter reverencial en el siglo XIX al margen de la tradición discursiva institucional y en ámbitos sociales asimétricos, como puede ser el de la relación entre esclavo y amo. A modo de síntesis, en el Cuadro 5 presentamos una versión unificada de algunos de los datos ya analizados.

Como surge de la lectura del cuadro, en la tradición institucional -en que la sintaxis de la forma es más compleja- los usos de su merced son delocutivos, con la posible excepción de algunos usos de difícil interpretación, y todos, reverenciales, dirigidos por un individuo que detenta menos poder a otro con más poder. En todos los casos se trata de autoridades, salvo por los ya mencionados contextos dudosos en que podría tratarse de conocidos con autoridad, aunque sin el ejercicio de su función al momento de la comunicación escrita.

En la tradición interpersonal, los datos encontrados muestran mayor complejidad, ya que se registran tanto usos referenciales como de tratamiento, con la excepción del siglo XVII, en que no se registran tratamientos. En los siglos XVI, XVII y XVIII, los usos referenciales se dan en relaciones de igual poder, en tanto que el de su merced se destina a familiares y conocidos dentro del mismo grupo social. Lo mismo ocurre con los usos de tratamiento en el siglo Xvi, aunque, como oportunamente indicamos, los casos encontrados pueden tener más de una lectura. Su merced como tratamiento en el siglo xviII se presenta de manera exclusiva en relaciones en que el locutor tiene menos poder que el alocutario, y siempre se da entre miembros de la familia. El panorama cambia en el siglo xIx, cuando se constatan también relaciones asimétricas, pero con actitud reverencial, y no deferencial, por parte del locutor.

Si bien este trabajo no se concentra en el paso de los usos delocutivos a los alocutivos, el haber realizado una descripción totalizadora del devenir de su merced permite afirmar que sus empleos actuales se originan en la tradición discursiva interpersonal. Esta tradición, recordemos, situada en el polo propio de la inmediatez comunicativa, puede manifestarse discursiva- 


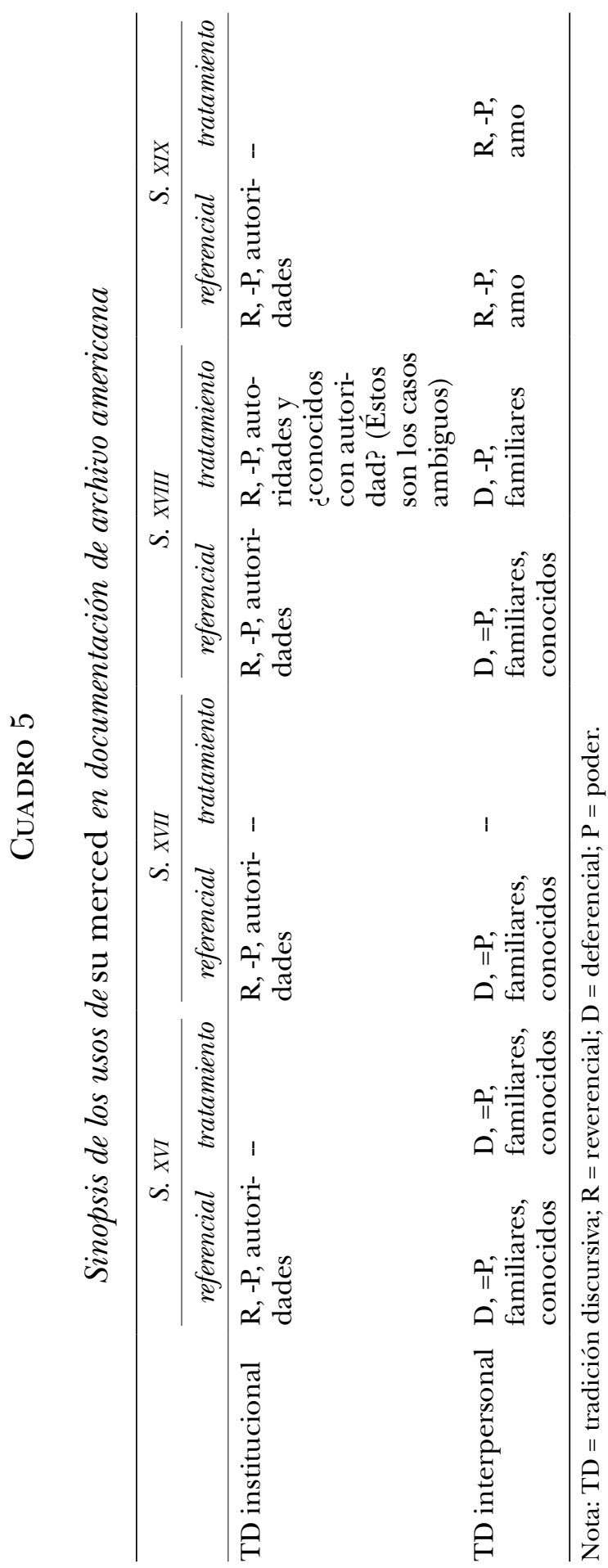

Nueva Revista de Filología Hispánica (NRFH), LXVIII, 2020, núm. 1, 105-136 ISSN 0185-0121; e-ISSN 2448-6558; DOI: 10.24201/nrfh.v68i1.3584 
mente en diferentes géneros; en este caso lo hace sobre todo en cartas entre particulares, pero también en episodios dialogales incluidos en expedientes.

Debemos buscar el origen de su merced alocutivo en la frase nominal su merced, expresión de deferencia ante un igual y de pertenencia a un grupo (noble). Será ésta la forma que se gramaticalice y alcance, en muchos casos de la actualidad, empleos pronominales. En la tradición discursiva interpersonal encontramos la clave para comprender el contexto de pervivencia de su merced en relaciones de poder desigual, tal como vemos en los usos del siglo xıx. Una investigación como ésta, basada en documentación amplia, permite afirmar que la hipótesis de Granda (2007), según la cual habría una primera etapa en que su merced se emplea en situaciones de poder desigual, no es de recibo. Nuestros datos del siglo xvi (utilización de la fórmula entre hablantes de igual poder y del mismo grupo) confirman el uso descrito por Correas (1626, p. 233): "De Merzed usamos llamar á las personas á qien respetamos, i debemos ó qeremos dar honra, como son Juezes, Caballeros, Eclesiásticos, Damas i jente de capa-negra, i es lo más después de Señoría". Algunos párrafos más adelante, aclara: "hablando del ausente i $3^{\mathrm{a}}$ persona dezimos Su-merzed, i en plural Sus-merzedes" (p. 235). No cabe duda de que se trata de un fenómeno de raigambre en el español europeo, tal como lo demuestran los casos del siglo XVI escritos por migrantes en América (algunos de los cuales citamos aquí) y tal como han señalado enfáticamente Calderón Campos y García Godoy (en prensa). Nuestros datos añaden que la forma se presenta históricamente como panhispánica con cierto énfasis en documentos colombianos, lo que podría deberse a características del corpus, aunque la coincidencia con uno de los lugares donde su merced se ha conservado no puede dejar de advertirse. Asimismo, la evidencia analizada permite afirmar que el desarrollo de la forma avanzó de manera distinta a la propuesta por Calderón Campos y García Godoy (en prensa) al mostrar dos evoluciones distintas y paralelas, en una de las cuales se constata desde el principio el empleo de su merced en contextos familiares.

Los usos en la comunicación interpersonal, que en los siglos anteriores se daban en contextos familiares o entre conocidos, se desplazan en el siglo xix a vínculos como los que mantenían esclavo y amo, un tipo de relación ya analizado, con datos tomados de la literatura, en Álvarez López y Bertolotti (2013). Estos 
usos del siglo XIX muestran que su merced se emplea en contextos sociales de desigualdad de poder, en los cuales se podría identificar el origen de los actuales usos de la forma, si tomamos en cuenta que algunos de los panoramas descriptivos de hoy en día aluden a la presencia de su merced en boca de hablantes, como los que acabamos de mencionar (esclavos, sirvientes, hijos), en estadios anteriores de la lengua ${ }^{7}$.

La sintaxis de su merced interpersonal es muy estable, con alguna variación fónica en el siglo XIX que podemos deducir de la ortografía su mercé o sumerced (principios del s. XVIII en EE. UU. y fines del siglo XVII en Colombia, respectivamente). Interpretamos estos datos como los primeros síntomas fónicos de un proceso de gramaticalización. La relación hecha entre el análisis gramatical de su merced y las dos tradiciones identificadas muestra que en la institucional el recurso a la aposición es abundante; sin embargo, también aparece con elevada frecuencia el sintagma su merced sin aposición. Los sintagmas apositivos responden a tres estructuras: dos de aposición especificativa y una de aposición explicativa; las especificativas son del tipo [AB] (como "su merced Josep de Gareca") y [A de B] (como "su merced del dicho alcalde"); las explicativas son del tipo "su merced, el señor teniente". El grado de especialización de su merced como forma de hacer deixis a cargos oficiales es creciente. Al mismo tiempo, la lectura en que $\mathrm{B}$ recibe lo atribuido por $\mathrm{A}$, esto es, algo así como dicho alcalde es un su merced, se va perdiendo en detrimento de otras aposiciones. En otras palabras, su merced como elemento que atribuye una identidad de clase se convierte en deíctico ocupacional, borrando así los límites que normalmente se establecen en los trabajos sobre formas nominales de tratamiento entre honoríficos y ocupacionales.

Establecida la existencia de estas dos vidas de su merced, podemos afirmar que, caído el mundo colonial, su merced en la tradición institucional desaparece, producto de los reflejos culturales de las transformaciones políticas. Con el cambio de la institucionalidad no deja de haber autoridades ni cargos, pero éstos no se designan con el título de su merced, que pertenecía a una tradición cortesana. En cambio, su merced interper-

7 Sigue pendiente de examen, más detallado y a fondo, con las enormes dificultades empíricas que ello implica, el papel de criados y criadas africanos o descendientes de africanos en la educación lingüística de varias generaciones de americanos de familias "pudientes". 
sonal, que en sus comienzos significaba 'deferencia dentro de un mismo grupo' ( siglo XVI), termina codificando 'desigualdad de poder' y 'reverencia' en el siglo xix. Esta evolución transcurre en un ámbito en que su merced como marcador de grupo social ha perdido sentido en el siglo xIx; sin embargo, para otros grupos de hablantes resultó una forma pasible de reutilización para expresar desigualdades de poder. Entendemos que ese reciclado lingüístico pudo haberse dado en la oralidad de grupos sociales que no habrían adquirido completamente las tradiciones discursivas propias de la escritura y que no tenían conocimiento de todos sus registros. La carta de 1809 analizada arriba es buen ejemplo de lo que acabamos de señalar. En el caso de los esclavos, el poco acceso que tenían a las tradiciones de la escritura se suma al hecho de que eran hablantes o descendientes de hablantes de español adquirido informalmente como segunda lengua, personas que podían modificar la lengua durante ese proceso de adquisición.

\section{Consideraciones finales}

Descriptivamente, hemos trazado el panorama diacrónico de su merced en América con base en datos empíricos hasta ahora no explorados, además de analizar cuidadosamente tanto las formas alocutivas como las delocutivas.

Metodológicamente, queremos destacar dos cuestiones. Por un lado, la relevancia de analizar el cambio lingüístico, sin partir de los resultados, con una mirada atenta al proceso, que nos permitió establecer la existencia de dos derivaciones de su merced. Por otro, la absoluta pertinencia de la complementación de las fuentes. Surge de la discusión que las fuentes de archivo y las literarias no deben tomarse como contrapuestas, sino como complementarias, siempre teniendo en cuenta que las caracterizaciones literarias de variedades vernáculas pueden exagerar rasgos, pero, generalmente, no al punto de hacer que los personajes pierdan su verosimilitud. Esta misma elaboración literaria proporciona ejemplos de interpretación no ambigua del uso de su merced. Como se dijo reiteradamente, en los ejemplos extraídos de corpus históricos, aun en aquellos con acceso al texto completo, como es el caso del CORDIAM, resulta muy difícil recuperar todos los matices de las situaciones comunicativas 
en que dichos textos se han generado, incluso con una lectura cuidadosa de los metadatos.

Teóricamente, entendemos que este trabajo ofrece pruebas pertinentes de la relación entre cambio lingüístico y tradiciones discursivas al mostrar cómo su merced pervive a través de una tradición discursiva y se extingue en otra.

\section{REFERENCIAS}

\section{Corpus}

CORDIAM = Academia Mexicana de la Lengua, Corpus Diacrónico y Diatópico del Español de América (CORDIAM), www.cordiam.org [consultado el 24 de agosto de 2018].

CORDE = Real Academia Española: Banco de datos (CORDE) [en línea]. Corpus diacrónico del español, http:/ / www.rae.es [consultado el 4 de mayo de 2018].

\section{Referencias bibliográficas}

Adam, Jean Michel 1992. Les textes: types et prototypes, Nathan Éditions, Paris. Álvarez López, Laura y Virginia Bertolotti 2013. "Usos americanos de su merced en el siglo XIx”, Lexis, 37, 1, pp. 5-32, http:/ / revistas.pucp.edu. pe/ index.php/ lexis/ article/ view/6898.

BARTens, Ángela 2003. "Notas sobre el uso de las formas de tratamiento en el español colombiano actual”, https://cvc.cervantes.es/lengua/ coloquio_paris/ponencias/pdf/cvc_bartens.pdf [consultado el 4 de mayo de 2018].

Benveniste, Émile 1970. "L'appareil formel de l'énonciation", Langages, 17, pp. 12-18, doi : https://doi.org/10.3406/lgge.1970.2572.

Bertolotti, Virginia 2017. "Formas de tratamiento con posesivo en el español”, en La posesión en la lengua española. Eds. Concepción Company Company y Norohella Huerta Flores, Consejo Superior de Investigaciones Científicas, Madrid, pp. 297-324. [También publicado en Style in language. Ed. Thomas A. Sebeok, MIT Press, Cambridge, MA, 2017, pp. 253-276].

Brown, Roger \& Albert Gilman 1960. "The pronouns of power and solidarity", en Style in language. Ed. Thomas A. Sebeok, MIT Press, Cambridge, MA, pp. 253-276.

Calderón Campos, Miguel \& María Teresa García Godoy en prensa. "The European roots of the present-day Americanism su merced", en Address in Portuguese and Spanish. Studies in diachrony and diachronic reconstruction. Eds. Martin Hummel \& Célia Regina dos Santos Lopes, John Benjamins, Amsterdam-Philadelphia. 
Carrera de la Red, Micaela y Alexandra Álvarez 2004. “Tratamientos de cortesía en la elaboración de fuentes documentales de la etapa fundacional de la Provincia de Mérida (Venezuela)", en Pragmática sociocultural. Estudios sobre el discurso de la cortesía en español. Eds. Antonio Briz y Diana Bravo, Ariel, Barcelona, pp. 227-243.

Cepeda Ruiz, Cristal Yeseidy 2014. Usted, tú, sumercé y vos. Formas pronominales de tratamiento en el español de Bogotá (Colombia), tesis, Universidad Nacional Autónoma de México, México.

Correas, Gonzalo 1903 [1626]. Arte grande de la lengua castellana, publícalo por primera vez el Conde de la Viñaza, de la Real Academia Española, Madrid.

Covarrubias, Sebastián de 1611. Tesoro de la lengua castellana o española, Luis Sánchez, Madrid, http://ntlle.rae.es/ntlle/SrvltGUISalirNtlle [consultado el 30 de abril de 2018].

De Jonge, Bob y Dorien Nieuwenhuijsen 2009. "Formación del paradigma pronominal de las formas de tratamiento", en Sintaxis histórica de la lengua española. Segunda parte: La frase nominal. Ed. Concepción Company Company, Fondo de Cultura Económica-Universidad Nacional Autónoma de México, México, t. 2, pp. 1593-1671.

Fontanella de Weinberg, María Beatriz 1999. "Sistemas pronominales de tratamiento usados en el mundo hispánico”, en Gramática descriptiva de la lengua española. Dirs. Ignacio Bosque y Violeta Demonte, Real Academia Española-Espasa, Madrid, pp. 1401-1425.

García Godoy, María Teresa 2008. "La suerte de su merced en el español de Andalucía (s. XIX)", en Actas del VII Congreso Internacional de Historia de la Lengua Española. Eds. Concepción Company Company y José G. Moreno de Alba, Arco/Libros, Madrid, t. 2, pp. 1795-1810.

García Godoy, María Teresa 2012. "El tratamiento de merced en el español del siglo Xvinı", en El español del siglo XVIII. Cambios diacrónicos en el primer español moderno. Ed. María Teresa García Godoy, Peter Lang, Berlin-Oxford-Wien, pp. 111-152.

Granda, Germán de 2005. "La forma de tratamiento su merced en el área lingüística surandina”, Lexis, 31, 1/2, pp. 165-175, http:// revistas.pucp. edu.pe/index.php/ lexis/ article/ view/1898.

GRANDA, GERmán DE 2007. "Hacia la diacronía de una forma de tratamiento en el español: su merced”, Lexis, 29, 2, pp. 247-257, http://revistas.pucp. edu.pe/ index.php/ lexis/ article/ view/8390.

Hummel, Martin 2010. "El estudio de las formas de tratamiento en Perú", en Formas y fórmulas de tratamiento en el mundo hispánico. Eds. Martin Hummel, Bettina Kluge y María Eugenia Vázquez Laslop, El Colegio de México-Karl Franzens Universität Graz, México-Graz, pp. 375-398.

Gutiérrez Maté, Miguel 2013. Pronombres personales sujeto en el español del Caribe. Variación e historia, tesis, Universidad de Valladolid, Valladolid, http://uvadoc.uva.es/ handle/ 10324/2517.

Keniston, Hayward 1937. The syntax of the Castilian prose, The University of Chicago Press, Chicago, https:// hdl.handle.net/2027/uc1.\$b659432.

Koch, Peter 2008. "Tradiciones discursivas y cambio lingüístico: el ejemplo del tratamiento vuestra merced en español", en Sintaxis histórica del espanol y cambio lingüistico. Nuevas perspectivas desde las Tradiciones Discursivas. 
Ed. Johannes Kabatek, Iberoamericana-Vervuert, Madrid-Frankfurt/M., pp. 53-88.

LAPESA, RAFAEL 2000 [1970]. "Las formas verbales de segunda persona y los orígenes del «voseo»", en Estudios de morfosintaxis histórica del espanol. Eds. Rafael Cano Aguilar y M. Teresa Echenique, Gredos, Madrid, pp. 311-345.

López Serena, Araceli 2011. "La doble determinación del nivel histórico en el saber expresivo. Hacia una nueva delimitación del concepto de tradición discursiva", Romanistisches Jahrbuch, 62, 1, 59-97, doi: https:// doi.org/10.1515/roma.62.3.

Mestre Moreno, Pilar 2010. "Alternancia de formas de tratamiento como estrategia discursiva en conversaciones colombianas”, en Formas y fórmulas de tratamiento en el mundo hispánico. Eds. Martin Hummel, Bettina Kluge y María Eugenia Vázquez Laslop, El Colegio de México-Karl Franzens Universität Graz, México-Graz, pp. 1013-1032.

Montes Giraldo, José Joaquín 2000. Otros estudios del español de Colombia, Instituto Caro y Cuervo, Bogotá. (Publicaciones del Instituto Caro y Cuervo, 101).

Obediente Sosa, EnriQue 2009. "Formas de tratamiento en Mérida (Venezuela) durante el siglo Xviı", Boletín de Lingüistica, 21, 31, pp. 86-107.

Obediente Sosa, EnriQue 2010. "Visión diacrónica y dialectal de las formas de tratamiento en los Andes venezolanos", en Selected proceedings of the $12^{\text {th }}$ Hispanic Linguistics Symposium. Eds. Claudia Borgonovo, Manuel Español-Echevarría \& Philippe Prévost, Cascadilla Proceedings Project, Somerville, MA, pp. 87-96.

Pérez Guerra, Irene 1988. "La forma alocutiva su merced en la República Dominicana. Uso y funciones", Anuario de Lingüística Hispánica, 4, pp. 241-248.

Pérez Guerra, Irene 1989. "El sistema alocutivo en el español dominicano. Nuevos materiales y precisiones”, Anuario de Lingüística Hispánica, 5, pp. 143-204.

Placencia, María Elena 2010. "El estudio de las formas de tratamiento en Colombia y Ecuador", en Formas y fórmulas de tratamiento en el mundo hispánico. Eds. Martin Hummel, Bettina Kluge y María Eugenia Vázquez Laslop, El Colegio de México-Karl Franzens Universität Graz, MéxicoGraz, pp. 347-374.

RAE y ASALE 2009. Nueva gramática de la lengua española, Espasa Calpe, Madrid.

Rigatuso, Elizabeth 1994. Fórmulas de tratamiento y familia en el español bonaerense actual, Universidad Nacional del Sur, Bahía Blanca.

Rigatuso, Elizabeth 2009. "Discurso de incorporación a la Academia Argentina de Letras”, Boletín de la Academia Argentina de Letras, 73, pp. 349-412.

Ruiz Morales, Hildebrando 1987. "Desplazamiento semántico en las formas de tratamiento del español de Colombia”, en Actas del I Congreso Internacional sobre el español de América. Eds. López Morales, Humberto y María Vaquero, Academia Puertorriqueña de la Lengua Española, San Juan, pp. 765-775. 
Sáez Rivera, Daniel 2013. "Formación e historia de vuecencia en español como proceso de rutinización lingüística”, Iberoromania, 77, pp. 108-129, doi: 10:15157ibero-2013-0050.

SÁez Rivera, Daniel 2014. "Procesos de lexicalización/gramaticalización en la formación e historia de usía en español”, en Procesos de gramaticalización en la historia del español. Eds. José Luis Girón Alconchel y Daniel Sáez Rivera, Iberoamericana-Vervuert, Madrid-Frankfurt/M., pp. 159-186.

SchrotT, ANGEla 2017. "Las tradiciones discursivas, la pragmalingüística y la lingüística del discurso”, Revista de la Academia Nacional de Letras, 10, 13, pp. 25-57.

Uber, Diane R. 1985. "The dual function of usted: Forms of address in Bogotá, Colombia”, Hispania, 68, 2, pp. 388-392. 